Ankara Üniversitesi Ĕ̆itim Bilimleri Fakültesi Dergisi, yıl: 2005, cilt: 38, sayı: 1, 167-174

\title{
Eserleri ve Yaşam Öyküsüyle Saygıdeğer Hocam Prof. Dr. Saffet Bilhan
}

\author{
İsmail GÜVEN*
}

\section{Prof. Dr. Saffet Bilhan kimdir?}

Prof.Dr. Saffet Bilhan 1934 yılında Elazığ'da doğmuştur. Ankara Üniversitesi İlahiyat Fakültesi'nden 1959 yılında mezun olmuştur. Prof. Dr. Suut Kemal Yetkin, Prof. Dr. Bedii Ziya Egemen, Prof. Dr. Hilmi Ziya Ülken, Prof. Dr. Necati Öner gibi bilim insanlarının öğrencisi olmuştur. Gerçekte bu kişilerden almış olduğu akademisyenlik kişiliğinin sağlamlığ ve tutarlılığı kendisiyle çalıştığımız 14 yıllık dönemde de sürmüştür. Bilge kişiliğe sahip olma, bir akademisyen için ne kadar uygunsa Prof. Dr. Saffet Bilhan için de o kadar uygundur. Lisans öğreniminden sonra 1969 yılında Fransa'da Sorbonne Üniversitesi'nde Lisansüstü Eğitimini tamamlamış ve 1973 yılında doktor unvanını almıştır. Prof. Dr. Bilhan Fransa'da 1968 sonrası öğrenci olaylarının en hareketli döneminde bulunmuştur. Fransa'da bulunduğu bu dönemde de organizasyon becerisi ve karizmatik yapısıyla öğrenci derneklerinde faal olarak çalışmıştır. Fransa'daki Türk Öğrenci Dernekleri başkanlığı yapmıştır. Türk öğrencilerle birlikte Paris’te bülten çıkarmıştır. Fransa'da okuduğu süre içinde, Prof. Dr.Şahin Yenişehirlioğlu, Prof. Dr. İhsan Turgut gibi bilim adamlarıla Fransa'da aynı dönemi ve fakülteyi paylaşmıştır. Fransa'da Doktorasını tamamlamadan Fransızca yazabilme becerisine sahip olması ve zeki kişiliğiyle kendisini belli etmiş ve ilk makalelerini Fransızca yazmıştır. Bilim adamlığı kimliğini sosyal kimliğiyle de birleştirmesini bilmiştir. Simon de Bovier, J.Paul Sartre gibi felsefecilerle tanışmış ve fikir alışverişinde bulunmuştur. Fransızca, İngilizce, Almanca, Arapça ve Farsça'nın yanı sıra Osmanlıca'ya hakim olması dolayısıyla çok önemli eserlere imza atmıştır. Türkiye'ye döndükten sonra Ankara Üniversitesi Eğitim Bilimleri Fakültesi, Eğitimin Sosyal ve Tarihi Temelleri Kürsüsünde Doçent olarak göreve başlamıştır. 1988 yılında

*Yrd.Doç. Dr., Ankara Üniversitesi EBF. 
Profesör olmuştur. 1989-1992 tarihleri arasında Ankara Üniversitesi Eğitim Bilimleri Fakültesi, Eğitim Programları ve Öğretim Bölümü'nün başkanlığını yapmıştır. DTCF, İlahiyat Fakültesi gibi birçok fakültede dersler vermiş ve öğretim üyeliği görevlerinde bulunmuştur. Türkiye'de Eğitim Felsefesinin öncüleri içinde yer almış ve Eğitim Felsefesinin kurumsallaşmasını sağlamıştır. 2001 yılında Eğitim Bilimleri Fakültesinden emekli olmuştur. Ölümüne kadar (Nisan 2005) Felsefe Derneği'nde de aktif görevlerde yer almıştır. Eğitim Felsefesi, Eğitim Sosyolojisi ve Orta Asya Bilgin Türk Hükümdarlar Devletinde Eğitim-Bilim-Sanat, olmak üzere 3 kitap, çok sayıda makale, bildiri ve yazıya imza atmıştır. Kuşkusuz burada bunların tümüne yer vermek olanaklı değildir. Yalnızca bazı eserlerine hocamız hakkında bilgi vermek için başvurulmuştur. Kendisinin eğitim felsefesi kitabında yazmış olduğu gibi bilgelik içinde yaşamını devam ettirip saygınlığını sürdürmesi hocamızın gerçek değerini anlatmaya yetmez. Hazır cevaplığ1 ve nüktedanlığı beklide onun öz yaşam öyküsü anlatan en iyi iki kelimedir.

\section{ESERLERI}

Eğitim Felsefesi, Ankara Üniversitesi Eğitim Bilimleri Fakültesi Yayını, Ankara 1991.

Felsefe ve eğitime ilişkin derin bir bilgi birikiminin somutlaştığı bir eser 'Eğitim Felsefesi'; eğitimi felsefi açıdan kuşatmaya yönelik bir ürün. Dokuz bölümden oluşan eserde bir yandan Eğilim Felsefesinin genel felsefe içerisindeki yeri belirlenirken öte yandan analitik yöntemle eğitim kavramları çözümlemeye tabi tutulmaktadır. Birinci bölümde, insan bilimleri ve eğitim arasındaki ilişkilere yer verilmiş, felsefenin doğas1 çözümlenmiştir. Klasik felsefe geleneğinin ötesine giderek, felsefi akımlar yerine, insan bilimlerinde felsefenin yeri tartışılmıştır. Eğitimle ilgili kavramların tartışıldığı ve çözümlendiği ikinci bölümde ise, eğitim ve öğretim kavramlarının farklı kullanımları irdelenmiştir. Yer yer ansiklopedik bilgilere ağırlık verilmesi kanımca eğitimin önemli görülen sorunlarına dikkatlerin çekilmesini ve daha ileri incelemelere 1 şı tutmayı amaçlamaktadır. Sanat ve eğitim ilişkisinin de derinlikli bir biçimde ele alındığı eser, eğitime sanat açısından yaklaşmanın güzel bir örneğini sunmaktadır. Tüm eğitimcilerin ilgisini çekecek önemli bir kaynak. Eğitim felsefesi geleneksel eğitim felsefesi anlayışlarını sıralamaktan öte, eğitim felsefesine farklı bir yaklaşımla ele alınmıştır. Özellikle eğitim sisteminde ortaya çıkabilecek sorunlar ve düşüncelerin felsefi temellerini çağın gelişmeleri doğrultusunda yorumlamaktadır. 3. Bölümde ise, felsefi akımlar ele alınmıştır. Türk eğitim sistemine belirli dönemlerde hakim olan felsefi anlayışlar çözümlenmiştir. Bilgi ve bilgilenme başlığı altında ele alınan 4. 
bölümde ise, bilginin doğası ve bilginin oluşumuna felsefenin katkıları incelenmiştir. Felsefenin temel sorunlardan olan özne ve nesne arasındaki ilişkileri ve eylemleri çözümleyen bu bölümü, insanın doğasının diğer yönünü ele alan 5. bölüm izlemektedir. Özgürlük ve özerklik kavramları çözümlenmiştir. 6. Bölüm ise, doğal olarak eğitimde mesajın nasıl ve hangi yolla iletileceği ele alınmış, sanatın eğitim felsefesi ve eğitim içindeki yeri ile bilgi kaynağı olmasına ilişkin betimlemelere yer verilmiştir. 7. bölümde ise, insan doğası ve ürettikleri ele alınmıştır. Ontolojik temeller ele alınmıştır. Tarihsel çözümlemelere yer verilmiştir. Okul ve eğitim kavramlarıyla kültür arasındaki etkileşimlere yer verilmiştir. İnsan ve Eylemi başlıklı 8. bölüm ise, bireyin değer boyutunu ele almaktadır. Aksiyolojik incelemeyi, epistemolojik çözümlemeleri içermektedir. En son bölümde ise, son yıllarda önem kazanan, din eğitimi, laik eğitim, çevre eğitimi ve demokrasi eğitimi gibi kavramsal sorunlar ele alınmıştır.

Eğitim felsefesi kitabı hem eğitimci, hem öğretmen hem de karar vericilere yol gösterici nitelikte olan bir eserdir. Genel felsefi yaklaşımları özetlemek yerine temel kavramlar üzerinde tartışmaları geliştirmeye dayalı bir eser olarak her eğitimcinin okuması gereken bir yapıttır.

Eğitim Sosyolojisi, Dil ve Tarih-Coğrafya Fakültesi Yayını, Ankara, 1986 (Ank.Ün.Eğitim Bilimleri Fakültesi Yayını, Genişletilmiş 2. Baskı 1996).

Eğitim sosyoloji alanında yazılmış ilk önemli eserlerden birisidir. Dil ve Tarih-Coğrafya Fakültesi tarafından yayımlanmış olan bu eser, Eğitimin toplumsal boyutunu ele almaktadır. Eğitim aslında bireyin yaşamı boyunca süren bir alandır. Toplumsallaşma açısından en önemli araçlardan birisidir. $\mathrm{Bu}$ anlamda Eğitim Sosyolojisi taklitten uzak kendine özgü yöntemle yazılmış eğitimi tarihsel bir temel içinde, felsefi anlayışlarla yorumlayan sosyolojik yönden çözümleyen bir eser olma özeliğini taşımaktadır. Ele alınan konular yalnızca Eğitim Sosyolojisi alanının evrensel boyutlarını yansıtmaktadır. Bununla birlikte, yerel ile evrenselin bu kitapta özümsenmiş olduğunu görüyoruz. Örneğin, sanayileşme ve toplumlara etkisi ele alınırken, Türkiye'deki sanayileşme çabaları ve bunun dünyadaki genel yaklaşımdan nasıl farklı verilmiş olduğunu gördüğümüzde, Eğitim Sosyolojisi adlı eserin değeri kendiliğinden ortaya çıkmaktadır. Eğitim Sosyolojisi 6 Ana bölümden oluşmaktadır. Eğitim sosyolojisinin tarih, yöntem ve diğer alanlarla etkileşimini ele alan bölümün en önemli özelliği, eğitim sosyolojisinin yalnızca örgün eğitimle sınırlanmadan yaygın eğitimi de içine almasıdır. Organizmacı geleneğin ürünü olarak, toplumun alt katmalarının üst katmanlarla etkileşimi ve eğitim kurumlarının birbirleriyle etkileşimi somut örnekler ve Türkiye gerçekleri üzerinden, herkesin 
anlayacağı bir dille yazılmıştır. Çeşitli ülkelerdeki eğitim anlayışının karşılaş̧ırmalı olarak verildiği II. Bölüm aynı zamanda Türk Eğitimi'nin sosyolojisinin de bir haritasını bize sunmaktadır. III. Bölüm ise hem eğitimin sosyal ve tarihi temellerini bir arada ele alındığı bölümdür. Kavramsal olarak gelişen ve Sosyolojinin ve dolayısıyla eğitim sosyolojisinin temel kavramları 1şı̆̆ında eğitim sisteminin çözümlenmesi amaçlanmıştır. Kapitalizm, insan hakları ve eşitlik kavramlarının çözümlendiği bu bölümün en çarpıcı noktası, popüler konuların bilimsel bir yaklaşımla ele alınmasıdır. Sanayileşme, iç göç ve aşırı bireyselleşme ile çocuğun farklı olarak algılanması bütün kültürlerde kabul edilen bir noktadır. Örneğin Neill Postman (1986) Disappearance of Childhood adlı eserinde bu kaybolmay1 Aile'nin yerini alan kurumlarla özdeşleştirmektedir. Çocuk oyunları, giysiler vb. noktaların sosyolojik açıdan çocuğu yetişkinleştirdiği görüşündedir. Fransız geleneği etkisiyle ele alınmış olan 4. Bölümde bu kavramlar, Türkiye gerçeği açısından irdelenmiştir. Bu bölüm eğitim sosyolojisi için önemli konulardan biri olan "Çocuk" ve "Aile" ile "Toplumsal Kurumlar" üçgeninin eğitimsel boyutlarını ele almıştır.

Weber, Eğitimi ele alırken, insana yapılan yatırımın eğitimde somutlaştı̆̆ını bu nedenle ürünlerinin geç alınabileceğini söyler. İnsan Sermayesi Kuramının öngördüğü eğitim ve ekonomi ilişkilerin Eğitim Sosyolojisinin 5. Bölümünde yer alması bize eserin ne kadar önemli olduğunu bir kez daha kanıtlamaktadır. Ekonominin eğitim üzerine olan etkilerini, Sosyolojik kuramlar ve uygulamalar temelinde ele almaktadır.

Durkheim, eğitimi; yetişmiş kuşakların yetişmekte olan kuşakları farklı biçimlerde yetiştirmesi olarak algılar. $\mathrm{Bu}$ yetiştirmede, devletin rolü büyüktür. Devletler eğitimi ele alırken, Anayasa ve diğer yasal uygulamalarla inceler ve çözümlerler. Eğitim Sosyolojisi kitabının belki de en çarpıcı ve önemli bölümü de bu konuları ele alıp inceleyen 6. Bölümüdür. $\mathrm{Bu}$ bölümde, Türk Eğitim Sosyolojisi kavramlarının devletin bakış açısı ve resmi kaynaklarında nasıl yer bulduğu ele alınmıştır. Türk Eğitiminin akışını belirleyen, Anayasa, Hükümetler, Kalkınma Planları gibi temel dokumanlar bu çözümlemelerde birinci elden kaynak olarak verilmiş̧ir. Sonuç olarak, Eğitim Sosyolojisi kitabı, Türk Eğitim Sosyolojisi olarak, Hocam Prof.Dr. Saffet Bilhan'ın önemli eserlerinden biri olarak eğitim tarihine geçmiştir.

\section{Orta Asya Bilgin Türk Hükümdarlar Devletinde Eğitim-Bilim- Sanat, Türk Diyanet Vakfı Yayını, İstanbul: 1988.}

$\mathrm{Bu}$ çalışma özellikle İslamiyet öncesi Türk toplumlarının yaşamları ve bilim-sanat kültür kurumlarını kaynak dillerine dayalı olarak birinci elden işleyen eserdir. Eserin en temel özelliği Timurlular döneminin en göz alıcı yönleri ve ender rastlanan hükümdarların bilim ve sanata katkıları Türk tarihine katkı niteliğindedir. Dünya tarihi içinde az bilinen bir noktayı ele 
alan bu çalışma, özellikle hükümdarların bilim ve sanata verdikleri önemin somut göstergesi olarak karşımıza çıkmaktadır. Türklerin İslamiyet'i kabul etmelerinden sonra hükümdarların en önemli özelliği bilim ve sanata değer vermeleri ve hükmettikleri ülkelerin birçoğunu nadide eserlerle donatmaları ve bilim adamlarına sahip çıkmalarıdır. Bu çalışmanın asıl önemli yönü, ele alınan dönemde hükümdarların yazdıkları ya da bıraktıkları eserlerin birinci el eserler olmasıdır. Prof.Dr. Bilhan, bu çalışmasıyla Türk bilim ve kültür tarihine büyük katkıda bulunmuştur. Daha da önemlisi Türk-İslam kültür yaşamını inceleyebilmek için gerekli olan kaynak dillerinden yararlanılarak eserin yazılmasıdır. Kitabın temel bölümleri İslam öncesinde Türklerin yaşayışlarının ele alınması, İslamiyet'i kabul ile birlikte yaşam tarzında ortaya çıkan değişimleri temel almasıdır. Hükümdarların bilim, eğitim ve sanata katkılarını alt yapı araçlarıyla birlikte ele almıştır. Bu çalışmanın en büyük özelliği Türk tarihinin her alanında çalışan araştırmacılara yol gösterici nitelikte olmasıdır. Gerçekten de, Türk tarihinin en az bilinen yönlerini tarihsel olarak erken zamanda ele alışıdır. Görsel kanıtlarla zenginleştirilmiş olan çalışmada, tarihsel süreç ve akış şemaları ile zaman sorunu da çözülmüştür. Eserde Türklerin dünya uygarlığına hediye ettikleri oyunlar ve bilim-sanat eserlerine de yer verilmiştir. Orta Asya Türk devletlerini inceleyecek olan bilim adamlarına esin kaynağ 1 olmuştur. $\mathrm{Bu}$ nedenle eser her bakımdan ilklere imza atmıştır.

Fransa'da 1789 Öncesi Eğitim adlı makalede, Fransa'da eski rejim döneminde, kilisenin eğitim üzerindeki etkisinden söz edilmektedir. Kilise, öğretim işinde ilk sırayı almakta, okulları yönetmekte ve masraflarını karşılamaktadır. XVIII. Yüz yılla birlikte ise, devlet, eğitici görevinin bilincine varmaya başlamıştır. Bununla beraber kilise yine de bu konuda tamamen egemendir. Nantes Talimatının iptalinden sonra, Protestan okullarının kapatılmasına karar verilmiştir ve bunların yerlerini Katolik okulları almıştır. Kralın 1698 yılındaki bir tebligatıyla, tüm Fransa'da okula devam etme zorunluluğu getirilmiştir. Küçük okullar ülkenin her tarafına ve hatta kırsal bölgelere yayılmıştır. Reforma karşı olması nedeniyle devletçe desteklenen kilise, durumunu güçlendirmiştir. Bununla birlikte, erkek çocuklar değişik tarzlarda öğrenim görme olanağına sahip olmuşlarsa da, kız çocuklar bu konuda çok geride kalmışlardır. Erkek ile kadın arasındaki bu fark, Roma hukuk anlayışının, kadını erkeğe itaat etmeye zorunlu kılmasının ve kadının kendisini başarılı olarak, ev işlerine vermesi için kültüre ihtiyacı olmadığını varsaymasından kaynaklanmaktadır. Ayrıca, kilise erkek ve kız çocukların bir arada eğitim görmelerini yasaklamıştır. Kentlerdeki ve kırsal bölgelerdeki okullar arasında farklılıklar bulunmaktadır. Başlangıçta okullar paralıdır. Fakat, fakir çocukların kendi hallerine bırakılmamaları için, öğretmene, ek olarak, parasız öğretim vermesi kabul ettirilmektedir ancak, ögretmen parasız öğrencilere, daha aşağı derecede bir öğretim vermektedir. İki tür öğretmen vardır: esas anlamda öğretmenler ve yazar-öğretmenler. 
Birinciler okuma, yazma, ölçme ve hesap öğretmekteyken, ikincilerin ticari bir görevleri bulunmaktadır. Bunlar, defter tutmayı, aritmetik ve değişik yazı yazma çeşitlerini öğretmektedirler. Pamuk ve ipek dokumak için bir nevi çıraklık merkezleri biçiminde iş okulları da bulunmaktaydı. Sınavı kazanıp, genel meclis tarafından tayini yapılmış öğretmen, cemaat ile süresi bir, iki, üç, altı veya dokuz yıl olarak değișebilen bir mukavele yapmaktadır. Sınıf öğretmenleri, başpapazdan öğretmen yetki belgesi almadan öğretmenlik yapamamaktaydı. Öğretim, bir odası sınıf olarak kullanılan ve bir odasında da öğretmenin kaldığ yerlerde yapılmaktaydı. Okula başlama velilere bağlı idi. Çocukları üç veya dört yaşlarında okula göndermekte ve kısa bir süre sonra da çalıştırmak için geri almaktadırlar. Şehirde okula devam süreklidir, kırsal bölgelerde ise mevsimlere göre değişmektedir. Öğretmen kişisel yöntemle uygulamaktadır, öğrenci dersini almak için öğretmenin önüne gitmekte, birkaç dakika içinde dersini almakta ve yerine dönmektedir. Temel öğretim ayin, din esasları ve kutsal tarih metinlerinden oluşmaktadır. Öğretmenlerin masrafları cemaatler ve dini kuruluşlarca sağlanmakta ya da kilise tarafından ödenmekteydi. Öğretmen ayrıca, ek işlerde çalışmaktaydı. Cemaat arasında öğretmen, köy papazından sonra ikinci sıradadır.

XVIII. yüzyıla kadar Paris Üniversitesi dini niteliğini korumaktadır. Öğrenciler dört gruba ayrılmıştır. Önce, sanat fakültelerine devam etmekteler, burada sanat üstadı unvanını aldıktan sonra, yüksek fakülte denilen ilahiyat, hukuk ve tıp fakültelerine kaydolarak buralarda mesleki öğrenimi izlemektedirler. Din adamları, beyler, asiller, zenginler tarafından, fakir öğrencileri ve bursluları kabul etmek amacıyla kurulmuş olan kolejler zamanla öğrenim merkezleri haline gelmişlerdir. Kolejler gramer, sözlü ve yazılı anlatım ve felsefe konularında öğretim gerçekleştirmekteydi. $\mathrm{Bu}$ kolejde öğretmenlik yapabilmek için, sanatlar lisansı yapmış olmak ve ögretim faaliyetinde bulunmak için, kendi grubundan izin istemek gerekmekte idi. Önceleri, öğrenciler öğretmene aylık ücret ödemekte idiler, posta işleri devletin eline geçince, öğretmenlerin ödenekleri yaptıkları işlere göre saptanmıştır. Profesörlerin iki dersinde bulunma, diploma elde etmeye ve avukatlık veya sanatlar doktorası unvanını almaya yetiyordu. Fransiz Üniversiteleri bu dönemde bilimsellikten uzaklaşmışlardır.

90 Yıllık Bir Türk Öğretim Kurumu Buğra Han Tamğaç Medresesi Vakıf Belgesi adlı makale, İslamiyet'i ilk kabul eden ve iki yüz bin çadırlık bir aileden ibaret olan, ancak İslamiyet'i kabul ettikten sonra (MS 960), kisa zamanda Orta Asya'nın büyük bir imparatorluğu haline gelen Karahanlı Devleti'nin hükümdarı olan İbrahim Buğra Tamğaç tarafından kurulmuş olan medreseye ait vakıf belgesi ele alınmaktadır. $\mathrm{Bu}$ belgede vakfın kurulma amacı, sınırları, gelirlerinin nerelerde kullanılacağı ve medrese yöneticilerinin atanmalarına ilişkin maddeler yer almaktadır. 
Tıp Okulu Niteliğinde, 10 Yüzyıllık Türk Hastanesi Vakıf Belgesi'nde de, Tamğaç Buğra Han'ın kurmuş olduğu hastane için bağışladığ yerler ve bu hastanenin kuruluş amac1 ve yönetim şekli anlatılmaktadır. $\mathrm{Bu}$ belge, belgelere dayalı tarih çözümlemesini yapma konusunda önemli bir ilke imza atmıştır. Tıp tarihi ve dolayısıyla bilim ve eğitim tarihini sosyal yönüyle ele alıp inceleyen bu çalışmanın ana kaynaklar ve birinci elden kaynaklardan hazırlanmış olması ve ilk olarak Prof.Dr. Saffet Bilhan tarafindan yayımlanmış olması yapılan çalışmalara öncü niteliğindedir. Prof.Dr. Bilhan'ın akademik kişiliğini ve araştırmacı kişiliğini her yönüyle yansıtan bu tür çalışmalar Türk eğitiminin ana kaynaklarını araştıranlara da esin kaynağı olmuştur.

Büyük Fransız İhtilali ve Türk Devrim Hareketleri adlı makalede Fransız İhtilali'nden önce Avrupa'daki eğitim incelendikten sonra Osmanlı Eğitim sistemine geçiş yapılmıştır. Buna göre, Avrupa'da, önceleri laik bir anlayışla gerçekleştirilen ve çocuğa belirli beceriler vermeyi amaçlayan eğitim zamanla dini bir nitelik kazanmıştır. Osmanlılarda da durum hemen hemen aynıdır. Osmanlı Devleti'nde din ayrilıkları ve bundan kaynaklanan eğitim ve öğretim kurumları ayrılıkları söz konusudur. Fakat bunlar, Osmanlı toplumunda ayrılıklara neden olmamıştır. Batı Avrupa din ve mezhep kavgaları ile çalkalanırken, ne Osmanlılarda, ne de Diğer Müslüman Türk Devletleri'nde din ve mezhep savaşı olmamıştır. Ancak, eğitimin bir devlet politikası olarak ele alınmamış olması, cemaatlerin ve halkın kendi örgütsel organlarına terkedilmiş bulunması dolayısıyla, ülke bireylerinin ve grupların yönlendirilmesi üzerinde Devlet kontrolü asgariye inmiştir. Diğer yanda medreseler de otorite boşluğu içerisinde ve devletin denetimi dışında kalmışlardır.

Fransa'da ihtilalin patlamasını etkileyen etmenlerden biri de eğitimdir. Eğitimle ilgili geçerli projeler ve yasalar hazırlanmamış olmakla beraber, düşünürlerin etkisiyle ögretim kurumları ve üniversitelerin durumu birer sorun olarak görülmeye başlanmıştır. Fransa'nın bilinçlenmesine Fransa dışından bazı düşünürlerin de etkisi olmuştur. ihtilal zamanı Fransız halkı eğitim olayından habersizdir. Çoğunluğu serf ve yarı köle durumunda olan halkı en çok etkileyen, her Fransız'ın aynı derecede vatandaş olması sloganıdır. Fransız düşünürleri ise, mutluluğun ve bilinçlenmenin, kısaca vatandaş olmanın yolunun eğitimden geçtiğine inanmaktaydılar.

$\mathrm{Bu}$ dönemde Osmanlı'da, Türk halkı mahalle mekteplerinin, medreselerin birer sorun olduklarını bilmekle beraber duyarsız kalmaktaydı. Çünkü etkin bir entelektüel sınıf bulunmamaktaydı. Türkiye'deki azınlıklar ise, cemaat örgütlerine sahip olmaları, devletin bürokratik çarkı dışında kaldıkları, Batı devletlerini, özellikle Fransızları kendilerine koruyucu kabul ettikleri ve Türk dış siyasetini çok yakından izledikleri için modern gelişmelere daha kolay uyum sağlayabilmişlerdir. 
Fransız ihtilali Fransız eğitimine 28 büyük proje getirmiştir. $\mathrm{Bu}$ projelerin bir kısmı eski feodal eğitim sistemini yıkmaya yöneliktir, bir kısmı ise geçerli yeni sistemler getirmektedir. Nihayet 1833 yılında eğitim ve öğretim yeniden gündeme gelmiştir ve yeni bir eğitim reformu oluşturulmuştur. Okullar devlet ile kilise arasında bölüştürülmüştür.

1739 ihtilalini gerçekleştirecek koşullar Fransa'da hazırlanırken, Türkiye bu etkenin dışında kalmamıştır. Birinci Mahmut zamanından itibaren, Fransa'daki uyanış hareketleri doğrultusunda bazı girişimlerin başlandığına tanık olmaktayız. Fransız ihtilalinin asıl etkisi ise, Avrupa ile sürekli temas halinde bulunan entelektüel bir sınıfın oluşması ve örgütlenmesi ile başlamıştır. Matbaanın da Türkiye'ye girmesi ile haberleşme araçları yeni boyutlar kazanmış ve bu etkiyi hızlandırmıştır. Fransız ihtilalinden sonra Batıda yaygınlaşan ve toplumlara canlılık veren yeni fikir alanlarına açılmak zorunluluğunu duyarken, bir yandan da Batının Osmanlı Devleti'ni yıkma arzularına set çekme çabalarını sürdürmek zorunda olduğu açıklanmaktadır.

Asya Eğitim Felsefesine Genel Bir Tarihsel Yaklaşım adlı makalede eğitim akımları ele alınmıştır. Bu anlamda ilk olarak ele alınan ülke Çin'dir. Sırasıyla Çin toplumunda eğitim, kralların eğitim politikası, kamu düzeni, orduda eğitim, Çin toplumsal yaşamının oluşmasında eğitimin işlevi, geleneksel skolastik düşünürlerin işlevi, Konfüçyüs Öğretisi, toplumsal bilinci oluşturma yöntemi, eğitimin gerekliliği, sessiz eğitim, kavram karmaşıklığı ve kavram oluşturma sorunu, okul kavramı, çocukların eğitimi ve Çin eğitiminde birey ve toplumun yeri gibi konulara değinilmiştir.

Kuşkusuz Prof. Dr. Saffet Bilhan'ın bu çalışmaları yalnızca onun birkaç eserinden örneklerdir. Bazı çalışmalarını Arapça ve bazılarını da Fransızca yazmıştır. Kaynak dillerden okunup değerlendirilmesi gereken bu eserler, Prof. Dr. Saffet Bilhan'ın akademisyenliğini ve uluslar arası bilim alanlarında da gösterdiği başarının önemli göstergelerindendir. Yaşam öyküsünü onun kitabında T.S. Elliot'dan yapmış olduğu bir alıntıyla bitirmek istiyorum:

“- Bilgi nerede?

-Malumatın içinde kaybettik.

-Malumat nerede?

-Bilgeliğin içinde kaybettik?"

Peki bilge nerede? ne yazık ki çok erken kaybettik’”"

• Orijinal deyiş değiştirilerek verilmiştir.(İ.Güven). 


\section{SAFFET BILHAN'IN ESERLERI}

\section{KITAPLAR :}

1- Les Juristes Kanafetis de I'Asie Centrale â I'Epoque des Qarakhanides (Enseigmemen-Histoire-Philusophie) Juridiques (doktora tezi) Paris Hukuk Fakültesi, 1973.

2- Araştırmalar ve incelemeler Bibliyografyası (ortak çalışma: Fransızcası: Saffet Bilhan; İnglizcesi: Mine Tan), Ankara, 1976.

3- Orta Asya Türk Devletlerinde Eğitim Bilim ve Sanat Hareketleri (Doçentlik Tezi), Ankara 1978

4- Eğitim Sosyolojisi, Dil-Tarih ve Coğrafya Fakültesi yayını, Ankara 1986

5- Özel Öğretim Yöntemleri-Din ve Ahlâk Bilgisi Öğretimi (Beyza Bilgin'le ortak çalışma) Anadolu Üniversitesi, Açık Öğretim Fakültesi, Eskişehir 1987

6- Orta Asya Bilgin Türk Hükümdarlar Devletinde EĞíTiM-BİLİMSANAT, Türkiye Diyanet Vakfı yayını, Ankara. 1988

7- Eğitim Felsefesi, Ankara Üniversitesi Eğitim Bilimleri Fakültesi Yayınları, Ankara, 1991.

\section{MAKALELER}

1- Fransada 1789 Öncesi Eğitim (Fêlix Ponteil'den çeviri) I.Eğitim Fakültesi Dergisi, C.10, say1 1-2, 198

2- Fransada 1789 Öncesi Eğitim (Fêlix Ponteil'den çeviri) II.Eğitim Fakültesi Dergisi, C.13, sayı 1-2, 1980

3- Büyük Fransız İhtilâl ve Türk Devrim Hareketleri, Ankara Üniversitesi Eğitim Fakültesi Dergisi, Ankara 1981.

4- 900 Yıllık Bir Tür Eğitim Öğretim Kurumu, Buğra Han Tangaç Medresesi Vakıf Belgesi I, A.Ü.Eğitim Bilimleri Fakültesi Dergisi, Cilt 15, Say1 2, Ankara, 1982.

5- Tıp Okulu Niteliğinde, 10 yüz yıllık Türk Hastanesi Vakıf Belgesi II, A.Ü.Eğitim Bilimleri Fakültesi Dergisi Cilt: 15, Sayı 2, Ankara, 1982.

-Bu son iki belge ayrıca, MEGSB lığı Din Öğretimi Dergisi, Sayı 8-9 1986 sayısında yayımlanmıştır. 
6- İlk Çağlarda Türk Kültür Hareketleri, Milli Eğitim ve Kültür Dergisi, Say1 19, Ocak 1983

7-Timurlularda Bilim Politikası, Eğitim ve Bilim Dergisi, Cilt 8,Sayı 46, Ankara 1983

8-Atatürk'ün Eğitim Felsefesi, Eğitim ve Bilim Dergisi, Cilt 9, Say1 52, Ankara 1984.

9-Asya Eğitim Felsefesine Tarihsel Bir Yaklaşım, (ÇİN) Eğitim Bilimleri Fakültesi Dergisi,, C 17, Sayı 1-2, Ankara 1984.

10-Asya Eğitim Felsefesine Tarihsel Bir Yaklaşım, (HINT) Eğitim Felsefesi, Gazi Eğitim Fakültesi Dergisi, Cilt 1, Say1 1, Ankara, 1985

11-Asya Eğitim Felsefesine Tarihsel Bir Yaklaşım, 1 (MEZOPOTAMYA) Eğitim Bilimleri Fakültesi Dergisi, Cilt 17, Sayı 1-2, Ankara 1985.

12-Çağımızı Etkileyen Eğitim Felsefeleri (BÜYÜK FRANSIZ İHTİLALİ VE EĞİTIM), MEGSB.Din Öğretimi Dergisi, sayı 12-13, 1987

13-“Kışlanın Sivil Eğitimine Katkısı İle İlgili Sosyolojik Bir Yaklaşım” Türk Silahlı Kuvvetler Dergisi, Mayıs, 1987

14-Asya Eğitim Felsefesine Tarihsel Bir Yaklaşım (İRAN), A.Ü.Eğitim Bilimleri Dergisi C. Sayı 1988 (Baskıda)

15-Hilmi Ziya Ulken'in Çağdaş Türk Düşünce Tarihindeki yeri, Gazi Eğitim Fakültesi Dergisi Cilt 2, Sayı 2, 1988 (Baskıda)

16-Un Aperçu de la Philosophie du Droit Turo d'Asic Centrale (XI-XII ême siêcle) Dil-Tarih ve Coğrafya Fakültesi Felsefe Bölümü Araştırma Dergisi, 1988 (Baskıda)

\section{BILDİRI İLE KATILDIĞI ULUSAL VE ULUSLAR ARASI SEMPOZYUMLAR}

1- Konu : “Atatürk'ün Eğitim Felsefesi” Atatürk İlkeleri ışığında Türk Eğitim Sistemi Bilimsel Toplantısı. TÜBİTAK-18-20 Kasım 1981, Ankara

2- Konu : "Din Eğitiminin Amacı"

Türkiye I.Din Eğitimi Semineri, Ankara Üniversitesi İlahiyat Fakültesi 2325 Nisan 1981 (Atatürk'ün 100.Doğum Y111) 
3- Konu : İnsan-Felsefe-Bilim Sorunsalı, İnsan Problemi Açısından Felsefe ve Sosyal Bilimler Sempozyumu. Atatürk Üniversitesi Fen ve Edebiyat Fakültesi Felsefe Bölümü, 5-7 Ekim 1983 Erzurum.

4- Konu : "Politique de I" Enseignement Secondaire"

UNESCO-CODOESEE, November 16-18 in Ankara.

5- Konu : "Eğitim Bilimleri Fakültesi ve Eğitim Bilimleri Bölümünün Türk Milli Eğitim Sistemi İçerisindeki Yeri” I.Ulusal Eğitim Sempozyumu, Marmara Üniversitesi Atatürk Eğitim Fak.ve Teknik Eğitim Fakültesi, 24-30 Kasım 1986-İstanbul

6- Konu : Yunus Emre'nin Doğu Felsefesindeki Yeri

Yunus Emre'den Atatürk'e Türk Düşüncesi'nin gelişimi-88 Semineri. Anadolu Üniversitesi, Kültürel Çalışmalar ve Çevre Eğitimi merkezi 56 Mayıs 1988, Eskişehir.

Ayrıca kültür ve eğitimle ilgili TRT II'den radyo konuşmaları ve günlük gazetelerde makaleleri vardır. 